\title{
The effects of exotic seaweeds on native benthic assemblages: variability between trophic levels and influence of background environmental and biological conditions
}

Fabio Bulleri ${ }^{1 *}$, Rebecca Mant ${ }^{2}$, Lisandro Benedetti-Cecchi ${ }^{1}$, Eva Chatzinikolaou ${ }^{3}$, Tasman Crowe ${ }^{4}$, Jonne Kotta ${ }^{5}$, Devin Lyons ${ }^{4}$, Gil Rilov ${ }^{6}$ and Elena Maggi ${ }^{1}$

\begin{abstract}
Background: Biological invasions are among the most severe threats to marine biodiversity. The impacts of introduced seaweeds on native macroalgal assemblages have been thoroughly reviewed. In contrast, no attempt has been made to synthesize the available information on the effects of exotic seaweeds on other trophic levels. In addition, it has not been clarified whether the effects of introduced seaweeds on native assemblages vary according to background physical and biological conditions.

Methods: This protocol provides details of our proposed method to carry out a systematic review aiming to identify and synthesize existing knowledge to answer the following primary questions: a) how does the impact of the presence of exotic seaweeds on native primary consumers (across trophic levels) compare in magnitude and extent to that observed on native primary producers (same trophic level)?; b) does the intensity of the effects of the presence of exotic seaweeds on native benthic ecosystems vary along a gradient of human disturbance (i.e. from urban/industrial areas to extra-urban areas to pristine areas)?
\end{abstract}

Keywords: Biological invasions, Seaweeds, Consumers, Human disturbance, Biodiversity, Ecosystem functioning

\section{Background}

Biological invasions are an important component of global change, posing major threats to marine biodiversity [1]. The introduction of non-indigenous species can alter the structure and functioning of natural ecosystems, with potential repercussions for their ability to provide goods and services to humans $[2,3]$. Thus, assessing the impacts of introduced species on native assemblages is among the top priorities for ecologists.

In the marine environment, the spread of introduced benthic macroalgae can lead to their complete domination of substrata, strongly affecting native assemblages and biodiversity. The impacts of introduced seaweeds on native macroalgal assemblages have been thoroughly

\footnotetext{
* Correspondence: fbulleri@biologia.unipi.it

'University of Pisa, Pisa, Italy

Full list of author information is available at the end of the article
}

reviewed $[4,5]$. In contrast, no attempt has been made to synthesize the available information on the effects of exotic seaweeds on other trophic levels. This is at odds with mounting evidence indicating that exotic seaweeds can be consumed by guilds of native herbivores, which, in some cases, receive physiological damage through the ingestion of these novel sources of food [6-8]. For instance, the red pigment caulerpin, the most abundant secondary metabolite of the green exotic macroalga, Caulerpa racemosa, enters food chains and accumulates in the fish tissues [8]. Significant correlations among caulerpin tissue load, fish condition factor and hepatosomatic index suggest a possible detrimental effect of the dietary exposure to C. racemosa on Diplodus sargus. Under such circumstances, evaluating the magnitude of the impacts of introduced macroalgae at upper trophic levels (i.e. primary consumers) and how they relate to impacts at the same trophic level (i.e. on native

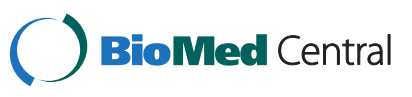


macroalgal assemblages) is of paramount importance for the management of invasions. Addressing bottom-up effects associated with invasions of primary producers will also help to refine current invasion theories that envision the success of invasive species in the introduced range as the result of the loss of consumers or parasites (e.g. enemy-release hypothesis [9]).

In addition, we can predict that the effects of introduced seaweeds on native assemblages will vary according to background physical and biological conditions. Biological (e.g. richness, relative abundance and evenness of species) and physical attributes (e.g. availability of resources; disturbance regimes) of recipient ecosystems are known to play a key role in determining the susceptibility to invasion of natural communities [10-13]. These same attributes may also determine the severity of the impacts of invaders that become established. In stressful environments, species are often limited by unfavorable environmental conditions, rather than competition [14]. Thus, we can predict that species in heavily degraded environments will not be limited by competition and are likely to be weakly affected by the presence of novel species. In well preserved, species-rich environments, competition is expected to be stronger, and resource uptake by exotic seaweeds could generate large negative effects on resident species.

Here, we propose to fill these two major gaps in our understanding of the impacts of biological invasions, taking advantage of the availability of a large body of empirical studies that have been carried out in marine environments.

\section{Objective of the review Primary questions}

We will look at the impacts of exotic seaweeds (species that have established outside their native range via human activities) on native assemblages, in order to ask the following questions: a) How does the impact of exotic seaweeds on native primary consumers (across trophic levels) compare in magnitude and extent to that observed on native primary producers (same trophic level)?

b) Do the effects exotic seaweeds on native benthic ecosystems vary in intensity along a gradient of human disturbance (i.e. from urban/industrial areas to extra-urban areas to pristine areas)?

For the first question (a), we will focus on native primary producer and consumer assemblages, populations and individuals (Table 1 ). We will extract response variables describing the structure of assemblages, the characteristics of populations and individuals, and the functioning of assemblages. Response variables will be standardized to enable comparisons between trophic levels. For the second question (b), we will not restrict our focus to primary producers and consumers. Rather, we will extend it to include the entire benthic assemblage, including benthic macroalgae, invertebrates and fish (Table 2). The geographic scope of this review will be global.

\section{Secondary questions}

a) The strength of consumer pressure and competitive interactions are known to vary with latitude (i.e. decrease towards higher latitudes; [17]). In addition, the number of established exotic species increases with latitude [18]. Thus, we will ask whether variation in the intensity of the effects of exotic seaweeds on primary producers and primary consumers depends upon latitude. In addition, we ask if latitude influences the comparison in magnitude and extent of the effects of exotic seaweeds between primary producers (same trophic level) and primary consumers (across trophic level).

b) Environmental conditions vary with latitude (i.e. solar radiation, temperature, productivity). Thus, we will

Table 1 Definitions of the components of primary question a

\begin{tabular}{|c|c|c|c|}
\hline Population & Exposure & $\begin{array}{l}\text { Outcomes } \\
\text { (response variables) }\end{array}$ & Comparators \\
\hline $\begin{array}{l}\text { Native seaweed and } \\
\text { herbivore } \\
\text { assemblages }\end{array}$ & $\begin{array}{l}\text { Introduction, } \\
\text { establishment } \\
\text { and spread of } \\
\text { exotic seaweeds }\end{array}$ & $\begin{array}{l}\text { Species/taxa diversity (e.g } \\
\text { richness, Simpson/Shannon/Berger-Parker } \\
\text { diversity indices), species/taxa evenness } \\
\text { (e.g. Pielou evenness index), } \\
\text { total community cover, } \\
\text { total community biomass, total biomass, } \\
\text { mortality, density, single species/taxa cover, } \\
\text { single species/taxa biomass, individual growth, } \\
\text { individual size, community productivity, } \\
\text { per capita reproductive output }\end{array}$ & $\begin{array}{l}\text { Invaded vs non-invaded units } \\
\text { Unit: organisms/individual/plots/ } \\
\text { treatments/areas/sites/locations/regions } \\
\text { Invaded unit vs Invader removal unit } \\
\text { Unit: organisms/individual/plots/ } \\
\text { treatments/areas/sites/locations/regions } \\
\text { Control unit (no Invader) vs } \\
\text { Invader transplanted unit } \\
\text { Unit: organisms/individual/plots/ } \\
\text { treatments/areas/sites/locations/regions }\end{array}$ \\
\hline
\end{tabular}


Table 2 Definitions of the components of primary question $\mathbf{b}$

\begin{tabular}{|c|c|c|c|}
\hline Population & Exposure & $\begin{array}{l}\text { Outcomes } \\
\text { (response variables) }\end{array}$ & Comparators \\
\hline $\begin{array}{l}\text { Native } \\
\text { benthic } \\
\text { ecosystems }\end{array}$ & $\begin{array}{l}\text { Introduction, } \\
\text { establishment } \\
\text { and spread of } \\
\text { exotic seaweeds }\end{array}$ & $\begin{array}{l}\text { Species/taxa diversity (e.g } \\
\text { richness, Simpson/Shannon/Berger-Parker } \\
\text { diversity indices), species/taxa evenness } \\
\text { (e.g. Pielou evenness index), total community } \\
\text { cover, total community biomass, single } \\
\text { species/taxa cover, single species/taxa biomass, mortality, } \\
\text { density, individual size, individual growth, per capita } \\
\text { reproductive output, community productivity, nutrient cycling } \\
\text { (e.g. nutrient uptake rate [N, P], nitrification rates), metabolism } \\
\text { (e.g. individual/community metabolic rate "B"; [15], oxygen consumption, } \\
\text { production of primary or secondary metabolites), decomposition } \\
\text { (e.g. abundance of particulate organic carbon [POC] or nitrogen [PON]), } \\
\text { carbon flux, respiration, sediment stabilisation (e.g. eroding pulse pressure, } \\
\text { sediment mass erosion), sediment mixing (e.g. sediment mixing depth, } \\
\text { bioturbation potential "BP"; [16]), resilience (transient differences in } \\
\text { spatial/temporal patterns of abundance of single or total species/taxa } \\
\text { or composition of assemblages in presence vs absence of the } \\
\text { invasive species), temporal (in)stability (e.g. temporal variance in } \\
\text { abundance of single species/taxa or total community; temporal } \\
\text { (dis)similarity indices), resistance (lack of differences in spatial/temporal } \\
\text { patterns of abundance of single or total species/taxa or } \\
\text { composition of assemblages in presence vs absence of the } \\
\text { invasive species), abundance of epiphytes, richness } \\
\text { (i.e. number) of epiphytes, invasibility } \\
\text { (presence or abundance of other invasive species) }\end{array}$ & $\begin{array}{l}\text { Invaded unit vs non-invaded unit } \\
\text { Unit: organisms/individual/plots/ } \\
\text { treatments/areas/sites/locations/regions } \\
\text { Invaded unit vs Invader removal unit } \\
\text { Unit: organisms/individual/plots/ } \\
\text { treatments/areas/sites/locations/regions } \\
\text { Control unit (no Invader) vs } \\
\text { Invader transplanted unit } \\
\text { Unit: organisms/individual/plots/ } \\
\text { treatments/areas/sites/locations/regions }\end{array}$ \\
\hline
\end{tabular}

ask whether variation in the intensity of the effects of exotic seaweeds along disturbance gradients depends upon latitude.

c) Exotic seaweeds can be present at different levels of abundance. Thus, we will ask whether the intensity of the effects of exotic seaweeds varies according to their abundance.

\section{Methods}

\section{Search strategy}

Scope of search

We will search the following databases for relevant literature and data:

\section{ISI Web of Science}

JSTOR

Bibliographies of all reviews identified as relevant during assessment of their full text will be searched for further material. In the case of papers reporting incomplete information, we will contact the authors to ask whether they might help in the retrieval of missing information. In order to maximize efficient use of limited resources, grey literature (reports, theses and non-published research works) will not be included. However, a test for publication bias and the potential impact of excluding grey literature will be carried out. References to the grey literature reported by peer-reviewed studies will be examined and included when matching the standards required [19].

\section{Search terms}

Search strings comprised of the terms reported in Table 3 will be used. The retrieved papers will be inserted to create a library in Endnote.

An asterisk (*) indicates a 'wildcard', which allows the database or search engine to look for multiple words that have different endings, e.g. estuar* captures [estuary OR estuaries OR estuarine]. Quotation marks ("”) around two words restricts the search to where that phrase occurs.

For these searches, the individual key words will be combined using 'Boolean' operators (restricting or expanding the searches using 'AND' and 'OR' to maximise the efficiency of searching). The individual terms or phrases listed within each of the columns (Exposure1, Exposure 2, Population, Outcome) will be combined by 'OR' within each category. These sets (one from each category) will be combined by 'AND' to generate the final set of results. Records from each database will be then integrated to yield the final list of papers. At the beginning, we will include all of the outcomes reported in Table 3, but the outcome list may be revised after having checked what is available in the literature.

Records of the search strategy used will be maintained to ensure repeatability and transparency and modifications will be made to the review protocol as necessary.

\section{Inclusion criteria}

Relevant studies will be selected through a 3-step process: 1) scanning article titles, 2) reading of the abstract and 3) reading of full text. This hierarchical 
Table 3 Strings of search terms

\begin{tabular}{|c|c|c|c|}
\hline \multicolumn{4}{|c|}{ Search terms } \\
\hline Exposure 1 & Exposure 2 & Population & Outcome \\
\hline $\begin{array}{l}\text { Alga*, } \\
\text { macroalga* } \\
\text { Seaweed* }\end{array}$ & $\begin{array}{l}\text { Alien*, invasi*, } \\
\text { introduced, } \\
\text { allochthonous, } \\
\text { nonindigenous, } \\
\text { non-indigenous, } \\
\text { "non native*", } \\
\text { non-native*, } \\
\text { exotic* }\end{array}$ & $\begin{array}{l}\text { marine, brackish, } \\
\text { estuar*, coastal, } \\
\text { shallow, sea*, } \\
\text { aquatic, maritime, lagoon*, } \\
\text { pelagic, benth*, } \\
\text { demersal, shore*, } \\
\text { intertidal, subtidal, } \\
\text { ocean*, bay, cove, }^{*}\end{array}$ & $\begin{array}{l}\text { Impact*, effect*, } \\
\text { influence, consequence*, } \\
\text { food-web*, "food web*", ecosystem*, biomass, } \\
\text { biodiversity,"biological diversity", communit*, } \\
\text { richness, diversity, abundance, evenness, cover, density, } \\
\text { "reproductive capacity", mortality, growth, assemblage*, } \\
\text { producti*, decomposition, "nutrient cycl*", oxygen, } \\
\text { carbon, flux, respiration, "ecosystem matabolism", } \\
\text { "sediment stabilisation", epiphyte*, "sediment mixing", } \\
\text { resilience, stability, resistance, invasibility, }\end{array}$ \\
\hline
\end{tabular}

process will speed up the retrieval of relevant studies whilst minimizing the probability of missing relevant information.

Studies will be deemed as relevant when including the subjects specified as Population, Exposure, Comparator and Outcome, as defined in Tables 1 and 2. We will begin by searching for studies examining a broad range of outcomes. Due to limited resources, we may later decide to exclude studies examining some of these outcomes. This decision will be based on the number of studies found for different outcomes, not on the apparent magnitude or direction of effects.

Only studies written in English will be considered, but there will be no restriction in regard to the date of publication or location. The decision not to consider studies written in languages other than English is justified by an efficient use of available resources. Information on the latitude, distance from major urban or industrial centers (either raw data or synthetic indexes of human pressures), and abundance of the exotic seaweed will be considered for the secondary questions. We will provide details of the reason why some studies have been rejected.

Both field and lab studies will be initially retained, as the "study setting" will be later considered as a possible effect-modifier (see Section Potential effect modifiers and reasons for heterogeneity).

Articles from meeting abstracts or book chapters will be assessed for relevance following the same criteria stated above. Original data or relevant information thereof will be sought directly from the authors.

The first two steps will be carried out by two investigators working together. Repeatability of the article selection process will be determined through the assessment of a subset of the literature database. Both investigators will work independently at the third step of the process (reading of full-text), and repeatability will be assessed via kappa analysis. If there are significant discrepancies in the assessments of the investigators, these will be discussed and the inclusion criteria will be amended for clarity, if necessary.
Potential effect modifiers and reasons for heterogeneity

It is likely that we will find additional sources of heterogeneity among studies. Outcomes may also depend on the:

- study type (lab, field, observational, experimental)

- scale of the study (spatial, temporal)

- design (replication, controls, confounding variables, $\mathrm{BACI})$

- execution (independence of samples, independence of treatments, randomization, sampling techniques and protocols)

- habitat type

- depth

- removal versus addition of the invader

- geographical region (Europe vs non Europe)

- species

- morphological groups of invaders

\section{Study quality assessment}

We will extract all relevant details from each full-text article selected in order to assess the quality of studies and to categorize the studies against the attributes summarized below:

1) Study type: Comparison between invaded and noninvaded plots / Comparison between invaded and invader removal plots/ Comparison between noninvaded and invader transplanted plots

2) Study location

3) Latitude

4) Longitude

5) Distance from major urban or industrial centers

6) Response variable(s)

7) Study type: lab*/ field ("studies done in the lab will be excluded for the primary question $b$ )

8) Study approach: observational /experimental

9) Spatial scale - extent: $<1 \mathrm{~km} 2 / 1-100 \mathrm{~km} 2 /$ spanning area $>100 \mathrm{~km} 2$

10) Spatial scale - grain (size of plots): plots $<1 \mathrm{~m} /$ plots $>1 \mathrm{~m} /$ individual /sub-individual (i.e. portions of an individual) 
11) Description of the hierarchical design - space

12) \# of spatial scales included: $1 / 2 />2$

13) Temporal scale - extent

14) Temporal scale - grain

15) Description of the hierarchical design - time

16) Number of temporal scales included: $1 / 2 />2$

17) Design - replication: Unreplicated / Replicated

if replicated: how many replicates?

18) Design - controls/reference sites: None / Procedural controls / Unmanipulated controls / Both

19) Design - CI

how many Control sites?

how many Impacted sites?

20) Design - BA

how many times Before?

how many times After?

21) Design - BACI

if Beyond BACI: how many Control sites? if Beyond BACI: how many Impacted sites? if Beyond BACI: how many 'Before' times? if Beyond BACI: how many 'After' times?

22) Design - confounding: Confounded/Not confounded

if High probability of confounding, list confounders

23) Execution - specify the sampling method

24) Execution - sample independence: Not independent/Probably independent/ Independent

25) Execution - treatment independence: Not independent $[20,21] . /$ Independent $[20,21]$

26) Execution - randomisation (allocation of sampling units): Neither/Haphazard/ Random

27) Confounding variables: Certainly present/Likely present/Not present

Studies that are considered of insufficient quality will be excluded from subsequent analysis (see section on confounding variables). However, the results of the quality assessment will be made available for each study (including studies excluded due to poor quality) in an appendix to the final review. The impact of excluding and including studies from the analysis that are categorized as different quality will be assessed in the review.
Determining whether replication has been carried out appropriately will be somewhat subjective, but the following criteria will be considered:

- do the controls appear to be spatially/temporally independent of the affected areas?

- do the replicates appear to be independent of one another in space and time (are they interspersed geographically, spread sufficiently in time, etc.)

- are controls and affected areas sufficiently similar (consider, for example habitat and substrate type, degree of exposure, salinity, proximity to human activities).

If clear evidence is available in the paper that all of these criteria are met, then the controls should be considered valid, if there is evidence of failure to meet any one of these criteria, the controls should be considered invalid and if it is not possible to make a proper assessment based on the information provided, then the study should be classified as 'unclear' in this regard.

If the authors refer to the replicates being assigned randomly, or make reference to the use of a random number table, they will be classified as being randomly assigned. If the authors refer to the allocation as haphazard, or make reference to a procedure such as throwing a quadrat over their shoulder, allocation will be classified as 'haphazard'. All others methods will be classified as 'other' and described so that their susceptibility to bias can be assessed.

A descriptive synthesis of the number and type of studies retained will be made available.

\section{Confounding variables}

We will record the presence of factors that may have caused the observed changes other than the presence of exotic seaweeds. These might include pulse or chronic sources of disturbance. For example, the occurrence of accidents due to human activities (e.g. oil spill, nuclear waste) or natural extreme events (e.g. storms; run-off due to heavy rains) during the execution of the study could mask the effects of exotic seaweeds. Details of these events will be taken into account to evaluate whether a study will have to be retained or rejected within the analysis. This, although clearly reported within our review, will be somewhat subjective.

For each paper, details of the confounding variables will be given when present. Confounding variables will be formally accounted for if possible; otherwise, studies will have to be rejected.

In the case of observational (i.e. not experimental) studies, we will carry out sensitivity tests according to the following categories used to score studies: 
CI

1 Control - 1 Impacted

$\geq 2$ Control $-\geq 1$ Impacted

BA

1 Before - 1 After

$\geq 2$ Before $-\geq 2$ Impacted

\section{$\mathrm{BACI}$}

1 Control - 1 Impacted : 1 Before - 1After

$\geq 2$ Control $-\geq 1$ Impacted: 1 Before -1 After

1 Control - 1 Impacted $: \geq 2$ Before $-\geq 2$ Impacted

\section{Beyond BACI}

The meta-analysis will be run including all the studies and repeated separately for each category of study to check how the category of the study can influence the results of the analysis. Of course, these analyses will be carried out only for those categories for which a sufficient number of studies is available. Categories will be reported in the summary Excel spreadsheet.

Papers suffering from one or more of the following major flaws could be rejected:

- Design - confounding: confounded

- Execution - sample independence: not independent

- Execution - treatment independence: not independent

- Randomization: no randomization in the allocation of experimental units to different treatments or, in the case of observational studies, of control sites.

Specific details of the reasons why a study has been deemed as suffering from one or more of the flaws mentioned above will be provided.

\section{Data extraction strategy}

We will extract data on the response variables listed within the Outcomes column in Table 1 and 2. These will include response variables describing the response at the level of native assemblages, populations and individuals. Specifically, we will extract means, measures of variability (standard errors, standard deviations, confidence limits) and sample sizes for plots or sites where the invasive species was present or absent. In addition we will extract information on invader abundance, and other potential effect-modifiers (see Section Potential effect modifiers and reasons for heterogeneity) and confounding variables (see Section Confounding variables).
We will also extract geographical coordinates. This will enable us to calculate the distance of each site from major urban or industrial centers, and use it as a proxy for human disturbance levels (relevant for primary question b). This will also allow us to assess the level of human pressure at each study site, by referring to the map of human impacts developed by Halpern et al. [22]. In addition, data on latitudes will be relevant to secondary questions a) and b). Authors will be contacted and asked to provide geographical coordinates, when these cannot be easily extracted from the papers.

Data will be extracted from tables or graphs presented in the selected papers. Extraction from graphs will be carried out by means of image analysis software, such as IMAGEJ or DATATHIEF. If data cannot be directly extracted from papers, the authors of the original study will be approached by e-mail, and asked to provide either raw data or relevant information (e.g. means, standard deviation/variance, sample size). Papers will be excluded when authors do not provide necessary information. In such cases, and in cases where only partial data is available, detailed information will be provided.

\section{Data synthesis and presentation}

For each study examined, a synthetic Excel spreadsheet will be generated in order to promote availability of relevant information. Data will be analyzed by means of meta-analysis techniques. It is likely that we will use random- or mixed-effect models. However, technical aspects, such as effect size measure (e.g. response ratio, Hedges' $d$ ), nature of the factor involved (fixed or random) will be dependent upon the type and quality of data. For instance, in the case in which we will use mixed models, the error structure of effect sizes might be modeled by means of fixed-effect model. Likewise, analyses might be run on effect sizes calculated for each of the relevant response variables reported by each experiment or on average effect sizes calculated using equal weight for all the individual effect size that are reported per experiment. These technical aspects have been widely described in the literature [23-26].

Results of the meta-analysis will be reported graphically using standard approaches. Forest plots will be used to represent effect sizes, and funnel plots and normal q-q plots will be used to assess whether there is any publication bias.

Sub-group analyses will be performed to assess the effects of potential effect-modifiers.

\section{Competing interests}

No conflicts of interest are declared.

\section{Authors' contribution}

All authors participated in the design of the study. FB drafted the manuscript. All authors read and approved the final manuscript. 


\section{Acknowledgements}

This research has received funding from the European Community's Seventh Framework Programme (FP7/2007-2013) under Grant Agreement No. 266445 for the project Vectors of Change in Oceans and Seas Marine Life, Impact on Economic Sectors (VECTORS)

\section{Author details}

${ }^{1}$ University of Pisa, Pisa, Italy. ${ }^{2}$ Bangor University, Bangor, UK. ${ }^{3}$ Hellenic Centre for Marine Research, Iraklion, Crete, Greece. ${ }^{4}$ University College Dublin, Dublin, Ireland. ${ }^{5}$ Estonian Marine Institute, Tallinn, Estonia. ${ }^{6}$ Israel

Oceanographic and Limnological Research, Haifa, Israel.

Received: 9 February 2012 Accepted: 13 June 2012

Published: 23 July 2012

\section{References}

1. Gray JS: Marine biodivesity: patterns, threats and conservation needs. Biodiv Conserv 1997, 6:153-157.

2. Williamson MH: Biological invasions. London: Chapman and Hall; 1996.

3. Pimentel D, Lach L, Zuniga R, Morrison D: Environmental and economic costs of nonindigenous species in the United States. Bioscience 2000, 50:53-65.

4. Smith JE, Williams SL: A global review of the distribution, taxonomy and impacts of introduced seaweeds. Annu Rev Ecol Syst 2007, 38:327-359.

5. Thomsen MS, Wenberg T, Tuya F, Silliman BR: Evidence for impacts of nonindigenous macroalgae: a meta-analysis of experimental field studies. J Phycol 2009, 45:812-819.

6. Trowbridge $C D$, Todd $C D$ : Host-plant change in marine specialist herbivores: ascoglossan sea slugs on introduced macroalgae. Ecol Monogr 2001, 71:219-243.

7. Box A, Deudero S, Sureda A, Blanco A, Alòs J, Terrados J, Grau AM, Riera F: Diet and physiological responses of Spondyliosoma cantharus (Linnaeus, 1758) to the Caulerpa racemosa var. cylindracea invasion. J Exp Mar Biol Ecol 2009, 380:11-19.

8. Terlizzi A, Felline S, Lionetto MG, Caricato R, Perfetti V, Cutignano A, Mollo E: Detrimental physiological effects of the invasive alga Caulerpa racemosa on the Mediterranean white seabream Diplodus sargus. Aquat Biol 2011, 12:109-117.

9. Kean RM, Crawley MJ: Exotic plant invasions and the enemy release hypothesis. Trends Ecol Evol 2002, 17:164-170.

10. Hobbs RJ, Huenneke LF: Disturbance, diversity, and invasion: implications for conservation. Cons Biol 1992, 6:324-337.

11. Davis MA, Grime JP, Thompson K: Fluctuating resources in plant communities: a general theory of invisibility. J Ecol 2000, 88:528-534

12. Stachowicz JJ, Fried H, Osman RW, Whitlatch RB: Biodiversity, invasion resistance, and marine ecosystem function: reconciling pattern and process. Ecology 2002, 83:2575-2590.

13. Bulleri F, Balata D, Bertocci I, Tamburello L, Benedetti-Cecchi L: The seaweed Caulerpa racemosa on Mediterranean rocky reefs: from passenger to driver of ecological change. Ecology 2010, 91:2205-2212.

14. Bertness M, Callaway RM: Positive interactions in communities. Trends Ecol Evol 1994, 9:191-193.

15. Allen PA, Brown JH, Gillooly GF: Global biodiversity, biochemical kinetics and the energetic-equivalence rule. Science 2002, 297:1545-1548.

16. Solan M, Cardinale BJ, Downing AL, Engelhardt KAM, Ruesink JL, Srivastava DS: Extinction and ecosystem function in the marine benthos. Science 2004, 306:1177-1180.

17. Pennings SC, Silliman BR: Linking biogeography and community ecology: Latitudinal variation in plant-herbivore interaction strength. Ecology 2005, 86:2310-2319.

18. Sax DF: Latitudinal gradients and geographic ranges of exotic species: implications for biogeography. J Biogeogr 2001, 28:139-150.

19. Vilà M, Espinar JL, Hejda M, Hulme PE, Jarosik V, Maron JL, Pergl J, Schaffner U, Sun Y, Pysek P: Ecological impacts of alien plants: a meta-analysis of their effects on species, communities and ecosystems. Ecol Lett 2011, 14:702-708.

20. Underwood AJ: Experiments in ecology. Cambridge: Cambridge University Press; 1997.

21. Winer BJ, Brown DR, Michels KM: Statistical principles in experimental 410 design. New York: McGraw-Hill; 1991
22. Halpern BS, Walbridge S, Selkoe KA, Kappel CV, Micheli F, D'Agrosa C, Bruno JF, Casey KS, Ebert C, Fox HE, Fujita R, Heinemann D, Lenihan HS, Madin EMP, Perry MT, Selig ER, Spalding M, Steneck R, Watson R: A global map of human impact on marine ecosystems. Science 2008, 319:948-952.

23. Gurevitch J, Hedges LV: Statistical issues in ecological meta-analysis. Ecology 1999, 80:1142-1149.

24. Hedges LV, Gurevitch J, Curtis P: The meta-analysis using response ratios in experimental ecology. Ecology 1999, 80:1150-1156

25. Osenberg CW, Sarnelle O, Cooper SD, Holt RD: Resolving ecological questions through meta-analysis: goals, metrics, and models. Ecology 1999, 80:1105-1117.

26. Rosenberg MS, Adams DC, Gurevitch J: Metawin: Statistical software for meta-analysis. Massachusetts: Sinauer Associates; 2000.

doi:10.1186/2047-2382-1-8

Cite this article as: Bulleri et al:: The effects of exotic seaweeds on native benthic assemblages: variability between trophic levels and influence of background environmental and biological conditions. Environmental Evidence 2012 1:8.

\section{Submit your next manuscript to BioMed Central and take full advantage of:}

- Convenient online submission

- Thorough peer review

- No space constraints or color figure charges

- Immediate publication on acceptance

- Inclusion in PubMed, CAS, Scopus and Google Scholar

- Research which is freely available for redistribution

Submit your manuscript at www.biomedcentral.com/submit
C) BioMed Central 